
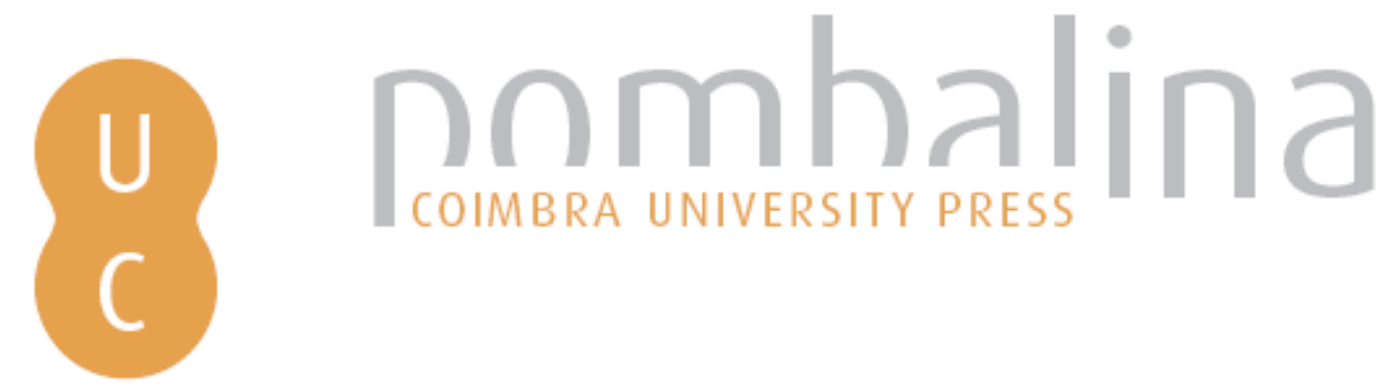

\title{
A Geografia em Alberto Sampaio: desde as explorações geográficas pela biblioteca do historiador vimaranense
}

\author{
Autor(es): $\quad$ Bandeira, Miguel Sopas de Melo \\ Publicado por: Imprensa da Universidade de Coimbra \\ URL \\ persistente: URI:http://hdl.handle.net/10316.2/43487 \\ DOI: $\quad$ DOI:https://doi.org/10.14195/978-989-26-1343-7_17 \\ Accessed : $\quad$ 26-Apr-2023 11:01:37
}

A navegação consulta e descarregamento dos títulos inseridos nas Bibliotecas Digitais UC Digitalis, UC Pombalina e UC Impactum, pressupõem a aceitação plena e sem reservas dos Termos e Condições de Uso destas Bibliotecas Digitais, disponíveis em https://digitalis.uc.pt/pt-pt/termos.

Conforme exposto nos referidos Termos e Condições de Uso, o descarregamento de títulos de acesso restrito requer uma licença válida de autorização devendo o utilizador aceder ao(s) documento(s) a partir de um endereço de IP da instituição detentora da supramencionada licença.

Ao utilizador é apenas permitido o descarregamento para uso pessoal, pelo que o emprego do(s) título(s) descarregado(s) para outro fim, designadamente comercial, carece de autorização do respetivo autor ou editor da obra.

Na medida em que todas as obras da UC Digitalis se encontram protegidas pelo Código do Direito de Autor e Direitos Conexos e demais legislação aplicável, toda a cópia, parcial ou total, deste documento, nos casos em que é legalmente admitida, deverá conter ou fazer-se acompanhar por este aviso.

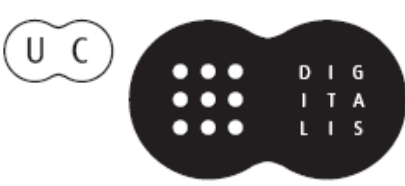




\section{FERNANDA CRAVIDÃO}

\section{IÚCIO CUNHA}

PAULA SANTANA

\section{NORBERTOSANTOS}

(ORG.)

\section{ESPAÇOS E TEMPOS EM GEOGRAFIA}

HOMENAGEM A ANTÓNIO GAMA

IMPRENISA DÁ UNIVERSIDADE DE COIMBRA COIMBRA UNIVERSITY PRESS

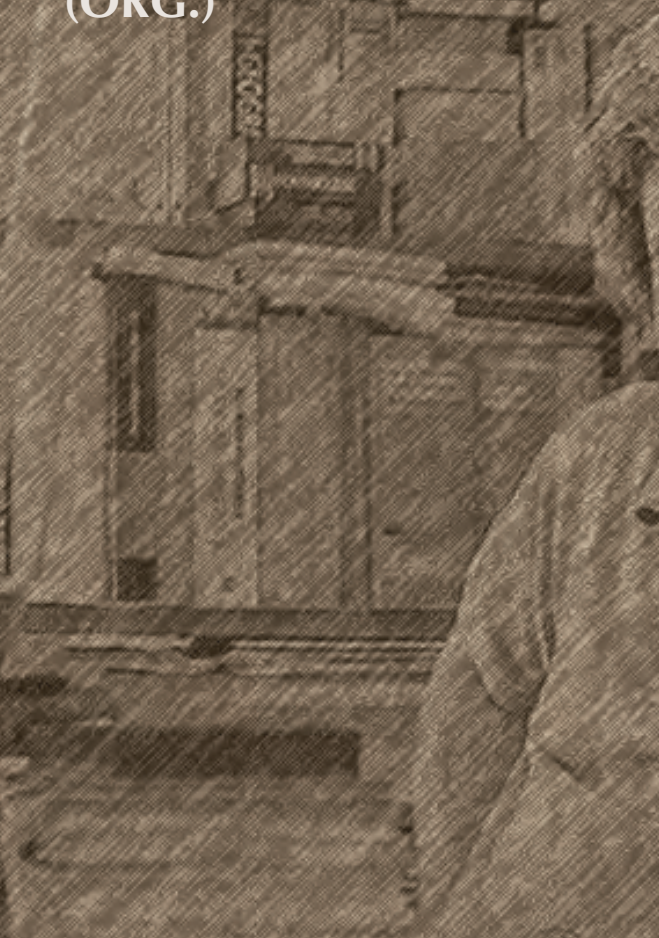




\title{
A GeOgrafia em Alberto SAMPAiO - DESDE AS EXPLORAÇÓOS GEOGRÁFICAS PELA BIBLIOTECA DO HISTORIADOR VIMARANENSE
}

\author{
Miguel Sopas de Melo Bandeira1/sopasbandeira@gmail.com \\ Instituto de Ciências Sociais da Universidade do Minho \\ e Vereador do Urbanismo e do Património Cultural \\ da Câmara Municipal de Braga
}

\begin{abstract}
Ao [António] Gama que está sempre presente, nosso bibliotecário de afetos e hermeneuta da imensa livraria que generosamente nos legou. Escutamo-lo ainda, à volta da fogueira nos acampamentos de geografia, convictos de que a sua voz se projecta nas esferas... se propaga na eternidade...
\end{abstract}

A biblioteca para mim, imagino que ao invés de uma grande maioria, nunca teve nada de sereno ou de acolhedor, pelo contrário, foi sempre um lugar de vertigem, angustiante até, pela impossibilidade do que promete, uma floresta luxuriante de variedade, de lugares recônditos, uma infinitude de novidades, de ideias, das histórias que os livros contêm e que uma vida inteira jamais pode abarcar. Enfrentar uma biblioteca tem, pois, sempre algo de venturoso, como

\footnotetext{
${ }^{1}$ Geógrafo do Instituto de Ciências Sociais da Universidade do Minho e vereador do Urbanismo e do Património Cultural da Câmara Municipal de Braga.
} 
o explorador que se embrenha na floresta em busca de um espécime e que, julgando que o vai encontrar, glosando H. Eco (1983), como quem procura um livro, depara-se com outras inesperadas variedades, isto é, com outros livros que nem suspeitava lá existissem...

Os livros, ainda que possam ser comparados às árvores de uma floresta, quando reunidos fazem uma biblioteca, estabelecem uma miríade de enraizamentos e ramificaçóes, interligados na cosmologia do tempo. Como dizia J. J. Borges (1941-44), 'a biblioteca é um modelo de universo'.

A biblioteca de Alberto Sampaio (1841-1908) configura um desses mundos que nos atrai para além do valor do documento em si e da perscrutação de supostos índices. Pelo dedilhar das lombadas; o abrir dos volumes em páginas que devolvem luz às letras adormecidas, depois de muitos e muitos dias passados na obscuridade do esquecimento; nos sobressaltam até, pelo desdobrar dos mapas e velhas cartografias, que exibem a delicadeza frágil de uma filigrana, cerzida pelo passar dos anos; de facto, é também a emoçáo que nos interpela, que nos dá a palpitante ilusão de proximidade ao nosso longínquo protagonista, dir-se-ia, que inspira algo devotamente afetivo. Essa será igualmente uma das magias da biblioteca, mais a mais quando se quer admitir que dela terão sussurrado muitas das "vozes" inspiradoras que hoje nos permitem desfrutar da leitura de Alberto Sampaio.

E no entanto uma biblioteca privada não sendo propriamente a pegada do seu proprietário, não é, também, sequer o único filão que explica ou justifica uma obra, mesmo quando o seu edificador se trate do próprio autor.

\section{Percursos, bibliotecas e leituras}

Cabendo-nos em sorte abordar a Geografia em Alberto Sampaio desde a sua biblioteca, porque toda a obra conhecida é, também, ela mesmo, a expressáo da própria geografia no alcance seminal do termo, temos na livraria do ilustre historiador alguns dos indícios mais sintomáticos e evidentes de filiação ao contexto do pensamento científico que marcou a época em que viveu e parte 
da expressão de conhecimento geográfico que desbravou. Naturalmente que, para além das congeminaçóes concetuais que a epistemologia da geografia hoje pode convocar, mesmo admitindo a assunção disciplinar explícita do que esta matéria e os seus oficiantes, incluindo o próprio Alberto Sampaio, poderiam então reclamar, é pacífico que toda a sua obra está humanamente prenhe de paisagem, de territorialidade sistemática, dos denominadores comuns que unificam a evolução do pensamento e da práxis geográfica. Desde logo, e sem mais, porque a denominação titular do fundamental dos seus trabalhos, tendo inequivocamente um tempo e um lugar, recria atmosferas e pinta paisagens, articula escalas, circunscreve territórios, precisa toponímias e marca símbolos, explora e localiza a relação entre os homens, os seus ambientes e o quadro físico-natural em que viveram. Mas, também, porque a sua obra se inscreve claramente numa admissível geo-história, que nós preferiríamos designar de geografia histórica, por ter a perenidade e o alcance de manter uma validade atual nos desígnios prospetivos do País, da nossa região, do compreender e do sentir telúrico das terras em que nascemos e vivemos... Sobretudo, num tempo em que buscamos desesperadamente resgatar a nossa identidade coletiva, em defrontar a autenticidade daquilo que nos constitui como nação.

É de todo insuspeito que a relação de Alberto Sampaio com os livros e os documentos foi uma constante ao longo da sua vida, por isso a sua biblioteca é tão-só a parte de um caminho percorrido. De facto, este conheceu e escrutinou as demais bibliotecas e acervos documentais que se abriram ao seu dispor.

Como o próprio nos confessa, no texto evocativo a seu amigo F. Martins Sarmento (1833-1899), a propósito da "preciosa biblioteca" que este legou à Sociedade que lhe foi dedicada, fora ele, Alberto Sampaio, quem catalogou esses livros, [e que verificou explicitamente terem sido] lidos meditadamente como mostram as marcas marginais, acrescentando em abono do seu alcance que, com franca generosidade (...) estava $(\mathrm{m})$ à disposição de quem o desejava (SAMPAIO: 2008, 482/3). Na composição da biblioteca de Martins Sarmento, afirma Pimenta, existe um impressionante número e extensão de referências 'clássicas', comparável ao [mesmo referente] da literatura critica correspondente (...), muitas obras que a Europa do momento produzia sobre os temas em que pretendia investigar 
(2007, 510). Aí encontramos alguns dos mais afamados historiadores latinos, como Heródoto, Políbio, Tito Lívio e outros, entre os quais, neste propósito, se destaca o inevitável Estrabão, de quem, todavia, o nosso ego preteria comparativamente a Plínio (Trindade, 1979: XIII).

As suas relaçóes de amizade proporcionaram, além da troca de ideias, incontornavelmente, também, a permuta de livros e textos, de que nos testemunha a sua abundante correspondência ${ }^{2}$, sobretudo, trocada com o amigo Luís de Magalhães (1859-1935).

Do mesmo modo foi frequentador assíduo da Biblioteca Pública Municipal do Porto, de que nos dá conta a sua epistolografia ${ }^{3}$, designadamente através da profusa expedição de correspondência emanada da Rua Formosa, n. ${ }^{\circ} 335$, e, depois, da rua da Alegria, n. ${ }^{\circ}$ 200; locais onde costumava hospedar-se nas suas frequentes estadias no Porto, por sinal bem cercanas da dita instituição ${ }^{4}$. Acrescente-se ainda o seu percurso académico, desde o Colégio de Landim (1852-56), passando episodicamente pelo Liceu de Braga (1856/57), até à Universidade de Coimbra (1858-63), que o pôs, certamente, em contacto com um filão indeterminável de obras literárias, muitas delas, seguramente, detentoras de conteúdos geográficos.

\footnotetext{
${ }^{2}$ Ex. cartas expedidas do Porto a Luís de Magalhães, onde refere: a 31 de maio de 1902, "irei a casa dele [Ric. Severo] pedir-lhe o Haupt" (filólogo alemão); ou, a 27 de agosto de 1908, "Talvez tenha de o incomodar por causa dum livro ou livros, a respeito do comércio inglês"; in Cartas de Alberto Sampaio... respetivamente p. 337, e p. 408.

${ }^{3}$ De que são exemplo, entre e outras, as cartas enviadas: a João de Oliveira Guimarães (Abade de Tagilde), (Boamense: 2 de Outubro de 1904), onde, a dado passo, A.S. refere, "Não conheço a obra de que me fala. Deve de facto existir na Biblioteca do Porto: e como estou em vésperas de voltar para lá, náo deixarei de a procurar, na primeira ocasiáo"; ou, entấo, as missivas enviadas a Luís de Magalhães (Porto: 5 de Setembro de 1902), (...) "para deixar em paz os grossos P.M.H., e seguir depois com outros autores, que não tenho, mas, penso, os haverá na Biblioteca de cá"; ou, ainda para o mesmo destinatário, (Boamense: 11 de Maio de 1904), "Por fim já cheguei a uma conclusão, precisando todavia de verificar umas passagens em certos autores, o que farei no meu regresso, na biblioteca do Porto. vid "Cartas de Alberto Sampaio..., respetivamente, pp. 27, 348 e 364 .

${ }^{4}$ Deixou definitivamente de frequentar com regularidade a Biblioteca do Porto, conforme afirma em carta dirigida a Jaime de Magalháes Lima, em 30 de Abril de 1907, Cartas de Alberto Sampaio... p. 131.
} 
Do mesmo modo que a bibliografia compulsada ao longo da sua vida extravasou a biblioteca que pode edificar, também é sabido que o conhecimento e o interesse geográfico da época ultrapassavam as publicaçôes da temática específica, e até mesmo da própria cartografia, que, julgando-se inalienável à matéria, já então era igualmente a de uma tecnologia indexável a distintas origens disciplinares.

\section{A geografia desde os livros e os mapas da biblioteca}

Como ponto de partida do inventário de que podemos dispor da Biblioteca de Alberto Sampaio5, doada pelos seus familiares descendentes ao Museu de Alberto Sampaio, em Guimarães, estáo reunidos especificamente vinte e duas entradas, num conjunto de 572 Itens, que foram catalogadas como sendo de Geografia. Dentro desta secção praticamente metade (11) constituem material cartográfico, mais ou menos avulso, que, se for adicionado aos Atlas, Diccionarios e outras obras de carácter genérico ou instrumental (manuais, apêndices e relatórios), sobrarão apenas dois ou três títulos, em edição francesa, que incluem uma referenciação específica à afirmação disciplinar da geografia da segunda metade de oitocentos. Naturalmente, no âmbito desta pequena série sobressai a monumental obra de Élisée Reclus, a Nouvelle géographie universelle: la terre et les hommes (1876-1884) ${ }^{6}$, que afirma o contacto direto de Alberto Sampaio com um dos marcos mais expressivos do paradigma dominante coevo das ciências geográficas na Europa. Do seu significado e alcance para a modelaçáo de uma mentalidade geográfica, sobretudo da segunda metade do século XIX, daremos conta detalhada mais adiante.

\footnotetext{
5 Biblioteca de Alberto Sampaio - catálogo - organizado pelo Museu Alberto Sampaio (policopiado) - Guimarães.

${ }^{6}$ Reclus, Élisée - Nouvelle géographie universelle: la terre et les hommes - Paris Hachette, 1876$-1884,9$ tomos.
} 
O trabalho de indexação considerou dez classes ${ }^{7}$, de entre as quais podemos encontrar inúmeros títulos, cujo conteúdo, inequivocamente, integra domínios do conhecimento que interessavam aos geógrafos e à geografia instituída da época.

Através do tema da agronomia, sobretudo, a área do conhecimento que o autor discorreu profusamente e dedicou muito das suas preocupaçóes ao longo da vida, encontramos o exemplo de B. Barros Gomes (1839-1910), Notice sur les Arbres Forestiers du Portugal (1878). Também, no âmbito da antropologia, arqueologia e etnografia, com indiscutíveis relações geográficas, apontamos as Chronicas Scientificas, em a Terra Portuguesa (1897), de A. A. Rocha Peixoto (1866-1909), onde se abordam aspetos patrimoniais e referências aos trabalhos de J. Leite de Vasconcelos (1858-1941), vultos da ciência e dos conhecimentos afins, com quem se correspondeu. No capítulo das ciências exactas e ciências naturais, notamos a existência de umas quantas obras que nos ajudam a compreender a acentuaçáo do contributo evolucionista, com evidentes implicaçôes na formação de um pensamento geográfico sistemático, então dominante. Desde logo, a edição francesa de Histoire de la création des êtres organisés d'après les lois naturelles : conferences... (1877) de Ernest Haeckel (1834-1919), obra que convoca A. v. Humboldt, Darwin, Goethe e Lamark, entre outros percursores da ecologia científica. Mas podemos igualmente avocar A. Brongniart (1838), H. Maré Davy (1876 e 1877), respetivamente, com: Tableau de terrains qui composent l'écorce du globe, an essai sur la structure de partie connue de la terre...; e, ainda, mais dois títulos sobre meteorologia, de H. M. Davy (1876 e 1877). No plano do trabalho de campo, táo caro à metodologia empírica, tanto dos naturalistas como dos geógrafos, vale a pena ainda referir o relatório da seç̧âo botânica da responsabilidade de Júlio A. Henriques (1838-1928), alusivo à expedição científica à Serra da Estrela de 1881, em que participou o seu amigo F. Martins Sarmento ${ }^{8}$. Da parte da economia e politica, várias são as presenças

7 1. Agronomia; 2. antropologia, arqueologia e etnografia; 3. ciências exactas e ciências naturais; 4. dicionários e elucidários; 5 . economia e política; 6. filosofia; 7. geografia; 8 . história; 9. línguas; 10 . literatura.

${ }^{8} \mathrm{Na}$ série de geografia foram incluídos os Relatórios das secçôes auxiliares: topografia, acampamento, de F. Ribeiro e L F. Ferreiro (1886). 
que nos podem ajudar a compreender a heurística do território, seja ela administrativa, pela referência à Histoire de L'emphytéose..., ou demográfica, pela asserção do trabalho de T. Malthus (1820), tão cara aos geógrafos da época.

Contudo, será no capítulo dos títulos atribuídos à disciplina de História que podemos encontrar conteúdos explicitamente comuns ao húmus geográfico, que decorrem do interesse direto que certas matérias têm para a formação do conhecimento do espaço geográfico histórico, bem como pelo testemunho renovador da historiografia produzida ao longo de oitocentos. Disso é exemplo o Précis d'Histoire et de la Géographie du Moyen-Âge; depuis da décadence de l'empire romain, jusqu'à la prise de Constantinople par les turc-ottomans, de C. Michels (1842). Por outro lado podemos ainda confrontar a expressão do conhecimento geográfico veiculado ainda pelo ideário da ilustração, como sejam as Memórias para a História Eclesiástica... de Jerónymo Contador de Argote (1732-47). Avançando para lá da arregimentação dos restantes títulos, desanexados da catalogação específica, pode-se ainda desfrutar de espécimes de elevada suscetibilidade geográfica, tais como as célebres, Corografia Portugueza e Descripçam Topografica (1868/69), de Pe. António Carvalho da Costa (1650-1715); e ainda, o Portugal Antigo e Moderno de A. Pinho Leal (1816-1884), subintitulado Diccionario geográfico, estatístico, chorográphico, heráldico, arqueológico, histórico, biográfico e etymologico de todas as cidades, villas e freguesias e de grande número de aldeias (1873/1890)9 .

Em todas as bibliotecas privadas deparamo-nos sempre com outro tipo de publicaçóes, que admitimos serem mais difíceis de avaliar quanto a um eventual impacte no percurso intelectual do autor. Referimo-nos às ofertas bibliográficas que lhe foram dedicadas ${ }^{10}$, aos folhetos e publicações avulsas, algumas até, menos eruditas e mais populares, como a Biblioteca das Maravilhas (contendo temas como: Trombas e Cyclones; Vulcóes e Terramotos, etc...); o Black's Guide, outros guias de viagem estrangeiros; e até relatórios das instituiçóes com que

\footnotetext{
${ }^{9}$ De que Alberto Sampaio faz uso (Tom. 6, p. 300) em carta enviada a Bento Carqueja informando da localização de Oliveira de Azeméis avançada por P. Leal, Cartas de Alberto Sampaio, opus cit, p. 20

10 ex. Meyra, J.M. (1907) - O Concelho de Guimarães - estudo de Demographya e Nosographya...
} 
se relacionou, ou fez parte dos órgãos sociais (Termas de Felgueiras, Banhos de Vizela, Companhia de Caminho de Ferro de Guimarães...). Queremos admitir, também, que destas publicaçóes algo de teor analítico terá contribuído para integrar o seu profundo conhecimento da natureza e do território.

Da série de geografia propriamente dita vimos já que a catalogação privilegiou o material cartográfico e os títulos mais explícitos. No primeiro caso, a maior parte da temática dos mapas versa as representaçôes africanas ${ }^{11}$, certamente associada ao acompanhamento que votava à política nacional e internacional, muito particularmente aos interesses coloniais portugueses que então convocavam o debate parlamentar e governativo, e que o autor acompanhava pelo jornais e na relação com os seus antigos condiscípulos de Coimbra. Tal interesse pode-se confirmar, por exemplo, nos recortes de jornais nacionais e estrangeiros alusivos, designadamente ao célebre contencioso diplomático entre Portugal e o Reino Unido que ficou conhecido pela questão do mapa cor-de-rosa (1886/90). Ou também através da correspondência que manteve com o seu estreito círculo de amigos mais diretamente envolvido na vida política, como Oliveira Martins (1845-1894), Luís de Magalhães, Jaime Magalhães Lima (1859-1936) e outros, da qual sobressaem ainda referências dos contactos havidos com o mais célebre cabo-de-guerra africanista da época, Mouzinho de Albuquerque (1855-1902), e o estadista João Franco (1855-1929).

Para além de mais uns quantos espécimes dedicados à ilustração da geografia política de então, surge também alguma cartografia do território nacional muito relacionada com a própria asserção da geografia da época. Isto é, uma temática disciplinar melhor reconhecida na esfera popular da grande divulgação pública do que no círculo fechado da erudição académica. Destacamos neste ponto as profusas e persistentemente disseminadas Cartas elementares de Portugal para uso das escolas, de Barros Gomes (1878) e, a Carta geographica do reino de Portugal de F. Perry Vidal $(1883)^{12}$, de que Alberto Sampaio fará uso

${ }^{11}$ Carta Hydrographica do Golfo da Guiné... (1845); Delta do Zambeze...(18--); General-Karte von Afrika...(1890); Hydrographia da Africa austral...(187-); Istmo do Suez... (1857).

12 Cartas de Alberto Sampaio... p. 20. 
instrumental nas suas pesquisas ${ }^{13}$ e em algumas citaçóes especializadas, muito concretamente no mais canónico dos seus textos geográficos, A propriedade e cultura do Minho (1885...).

Embora nem todos os atlas mereçam uma catalogação uniforme, a atestar essa recorrente interpenetração entre os conhecimentos geográficos, os históricos e os clássico-humanísticos, facto que, todavia ainda hoje subsiste, a presente série - que, por exemplo, exclui do frontispício geográfico o Atlas historique, généalogique, chronologique et géographique, de E. Las Cases (1829) - por outro lado, integra na disciplina de geografia o Atlas universel de géographie moderne, ancienne et du Moyen Âge... (180-), e o Atlas de géographie physique, politique et historique (1874), para uso nos liceus nos cursos de geografia e história.

Também, no plano instrumental da consulta, observamos dois exemplares do Diccionario geográfico abreviado, dedicados ao território nacional, respetivamente, de F. P. Maranhão (1852) e P. J. Marques (1853) ${ }^{14}$.

Por fim, no tocante aos títulos propriamente específicos em geografia, as poucas publicaçóes sobrantes do critério adotado, afiguram-se como sendo de natureza e alcance diversos.

Próximo ainda de uma finalidade consultiva de teor descritivo, exibe-se a Geographia e estatística geral de Portugal e colónias, de G. A. Pery (1875). Por outro lado, sobressaem duas obras editadas em 1860 dedicadas à reconstruçáo da geografia da antiguidade clássica, de que se destacam, a Géographie ancienne: comparée avec la géographie moderne, de Meissas e Michelot, e a Petite géographie ancienne..., de Blignières. Finalmente, mais não fosse pelo seu volume e formato, impóem-se-nos os tomos já referidos da Terra e os Homens (1876-1884), de Elisée Reclus (1830-1905), o geógrafo do determinismo geográfico e o libertário das causas emancipatórias e da fraternidade universal.

13 "Observo ainda que no mapa de Portugal publicado por Frederico Perry Vidal vem indicado um sítio, ou 2, com o nome de 'Sopellos' - entre Castelōes e Ossela. Não o encontro no P. Leal nem no dic. cor. q. tenho à mão (...)" escreve Alberto Sampaio a Bento Carqueja, de Boamense, em Julho de 1907, idibid, p. 25.

${ }^{14}$ Este último especifica os concelhos, comarcas, districtos, provincias, dioceses, oragos, freguesias, côngruas respectivas, legoas de distancia, correios e feiras... 


\title{
Alberto Sampaio, Elisée Reclus, e a afirmação de uma disciplina científica: configuraçôes implícitas e explícitas da geografia do final de oitocentos
}

\begin{abstract}
L'histoire n'est que la géographie dans le temps, comme la géographie n'est que l'histoire dans l'espace
\end{abstract}

Elisée Reclus (1905)

Para quem percorra as estantes envidraçadas que acolhem a biblioteca de Alberto Sampaio é inevitável que, das diversas séries de volumes existentes, o olhar do geógrafo privilegie os nove tomos da magna obra de J. J. Elisée Reclus, a Nouvelle géographie universelle: la terre et les hommes (1876-1884). De imediato ocorre-nos uma associação que, podendo náo ser mais do que isso mesmo, inspira-nos, porém, na busca de articulaçóes e dos nexos causais que fazem o fermento de toda a investigação e ensaio. No caso, releva-se a afinidade ideológica de Reclus, assumido communard do anarquismo ideológico, com Pierre-Joseph Proudhon (1809-1865) ${ }^{15}$, percursor e mestre dessa demanda. Sendo este, como é sabido, uma referência intelectual e influência declarada junto de algumas das principais figuras da geraçâo de setenta, particularmente, Antero de Quental, Oliveira Martins..., os condiscípulos de Coimbra e amigos mais chegados de Alberto Sampaio. Salvaguardando, contudo, que Sampaio se sentisse um monárquico convicto.

Ainda que o conceito de geografia aí vertido, por si só, não constitua um referente metodológico omnipresente e sistemático da obra de Sampaio, é inegável, porém, no âmbito do pequeno universo bibliográfico que nos convoca, que este veicule os rumos do conhecimento do sábio geógrafo francês ${ }^{16}$, constituindo assim, o principal marcador identitário da geografia disciplinar,

15 Cuja biblioteca contém o título, De la création de l'ordre dans l'humanité, P. J. Proudhon (1868), curiosamente, autografado por Antero de Quental.

16 Assim o designa Alberto Sampaio, In Plantas e Animais, III, A Propriedade e Cultura do Minho, I, O Minho Rural e Industrial (1884); Sampaio, A. - Estudos Históricos... II Vol. opus cit.,1979: 192. 
senão, e no mínimo, a linha de estilo deliberadamente científico-geográfica da sua obra de historiador. Dir-se-ia, não tanto pelo carácter kantiano que então poderia distinguir a natureza das matérias, mas, sobretudo, porque Elisée Reclus «adopte un point de vue quasi hégélien pour proposer une méditation sur le sens de l'histoire universelle envisagée du point de vue de la géographie. On est là dans l'univers des «grands récits» (Besse: 2005 : 5). Nesta perspetiva, a postura de Alberto Sampaio, que, nas suas próprias palavras, se assumirá como cultor de uma história sem personagens (Sampaio: '1979': 7), da terra e das suas gentes, reconhecidamente um pioneiro no campo da historiografia, afeiçoa-se igualmente à condição da geografia de E. Reclus, pela sua parte, o geógrafo do globo e da irmandade dos povos. Isto é, de acordo com Besse, «le géographe, au début du $\mathrm{xx}^{\mathrm{e}}$ siècle, est un témoin. Montrer le monde tel qu'il est, cela reste pour lui une tâche, à la fois sur le plan de la connaissance et sur celui de la morale» (2005: 11). Saliente-se, os atratores indissociáveis da obra do Mestre de Boamense.

De facto, pese a advertência auto consciente de Alberto Sampaio em reconhecer o seu trabalho despojado do drama das paixóes e dos jogos de interesses, ainda que com isso, confessa-o, limitando a capacidade de atrair leitores, especifica a dado passo ter por finalidade um alcance mais amplo, o de dar a conhecer as origens comuns às "gentes da sua terra, não os cultos íntimos do latim, mas dos outros que apenas podem ler ou ouvir na sua língua os feitos passados daquelas terras que lhes consumiam os trabalhos e os dias" (Trindade, 1979: VII). Num certo sentido, poder-se-á afirmar que Sampaio e Reclus se irmanam humildemente na mesma missão de serviço em prol do desígnio moral da disseminação do saber, adiante do reconhecimento académico, que, ainda assim, sublinhe-se, ambos igualmente desfrutaram ainda em vida.

Poderemos então considerar, para lá de uma geografia implícita, permanente, e decorrente da novidade historiográfica que a sua própria obra aporta, que há em Alberto Sampaio também uma geografia explícita, mais circunscrita aos parcos geógrafos que cita, e de que Elisée Reclus é, sem dúvida, um marco incontornável. A este propósito, não deixa de ser notável que a primeira ilustração de uma variedade de imagens selecionadas da geografia do globo, inserta 
nos folios frontispiciais do primeiro volume da citada obra, Reclus inclua uma cartografia das colónias de veteranos romanos ${ }^{17}$, representativa do parcelário rural de Faenza, em Itália. Mais precisamente, o tema do cadastro romano, um dos motivos centrais da reconstituição histórica de Alberto Sampaio, sobretudo desenvolvida nos primeiros capítulos de As Villas do Norte de Portugal.

De acordo com H. Capel a institucionalizaçáo da geografia em França ocorreu a partir dos anos de 1870 , sendo o positivismo e o evolucionismo o principal atractor "inspir[ador de] una parte de la obra científica de los primeiros maestros de la geografía francesa contemporânea" (Capel, 1988: 293). De entre as principais temáticas, as de maior pendor naturalista, daquilo que hoje designaríamos como sendo do âmbito da geografia física (a topografia/relevo, o clima, a vegetação e os solos), denotam uma expressão de maior dinamismo e de acentuação do sentido evolutivo da paisagem, por contraponto à visáo cénica, romântica, de carácter estático, que até aí vigorou, e de que a geografia imaginativa de Martins Sarmento (Pimenta, 2007: 474), seu amigo intelecto mais imediato, é disso um claro exemplo.

Para o geógrafo e epistemólogo espanhol, E. Reclus enquanto discípulo assumido de K. Ritter (1779-1859) - que já utilizava profusamente o método comparativo - ele é o primeiro a refletir na sua obra o impacto das teses de C. Darwin (1809-1882) na geografia, desde logo pelo seu carácter marcadamente evolutivo e de permanente mudança do espaço terrestre (Capel, 1988: 302). Reclus posiciona-se ainda como um determinista ambiental no método, por afirmar que a geografia de então, como nos refere Besse, citando I. Hacking, deve ser percebida nos campos de uma racionalidade observável, descritiva, comparativa, que se pode resumir ao domínio da história natural e que desenvolve um estilo próprio (Besse, 2005: 9). Nesta mesma ordem de ideias também Alberto Sampaio, sendo um historiador das raízes profundas e das razôes populares, da história das grandes tendências, ele é também um inequívoco cultor da história comparada (Trindade: XII), que não a da estrita administração das datas e da

17 - primeira figura (p.2), in Nouvelle Géographie... vol. I, «Colonies des Vétérans Romains», 1/356:000, gravé par Erhard, d'après la carte de l'Etat-Mayor autrichien, Faenza, Itália (c. Imola). 
política dos nomes sonantes. Recorrendo frequentemente às referências gerais de outras paragens e à bibliografia estrangeira, sobretudo francesa e alemã, da qual tira partido, pelo seu alargado conhecimento de línguas. Por outro lado, o historiador também privilegia a heurística da localização geográfica (Trindade, 1979: XVI e XIv), que sempre induz consideraçôes de história comparada, como são os exemplos que ele nos faculta, sobretudo da antiga Gália e Itália.

De facto, uma das dimensôes mais inovadoras da metodologia histórica de Alberto Sampaio decorre precisamente do privilégio que o autor consagra ao ambiente geográfico, económico e social (Mendes, 2008: 20). Ou seja, precisamente no modo como convoca a relação estreita entre a história e a geografia nos seus estudos. Veja-se como principal testemunho desse conceito - A propriedade $e$ cultura do Minho (1885...) - esse verdadeiro ensaio geográfico, dir-se-ia, de enquadramento num programa mais vasto de estudos regionais, sobretudo pelo conteúdo e organização que imprime à estrutura do texto. Este reparte-se por quatro capítulos (I - A Terra; II - O clima; III - Plantas e animais; e, IV-Os Homens), sendo os três primeiros dedicados a temas ambientais enquadradores, de rasto naturalista - os dois iniciais, designaríamos hoje, do foro da geografia física, e o terceiro da biogeografia - a antecederem a inevitável asserção etno-histórica, a mesma que, mais tarde, estabelecida em relação, viria a justificar o ponto de partida para a afirmação da geografia humana.

Sem se rever, ou sequer pressentir no dito prefácio, Alberto Sampaio, como oficiante da geografia dos finais de século, começa por nos advertir não ser um naturalista, desvinculando-se mesmo da especialidade dos três primeiros capítulos. Para tal, acrescenta no plano metodológico, ter recorri[do], de entre as poucas publicaçôes actualmente existentes, às mais autorizadas, preferindo documentos oficiais, sempre que os encontrou (Sampaio, 2008: 31).

Para o capítulo de abertura - A Terra - Alberto Sampaio vai basear-se nos trabalhos de B. Barros Gomes, sobretudo, nas famosas Cartas Elementares de Portugal (1878) e, com menor incidência, em G. Perry, Geografia e Estatística de Portugal e Colónias (1875). Para a geologia agrícola (1884/97) citará E. Risler, uma referência percursora desta matéria em Portugal, e ainda no iluminista Pe. António Carvalho da Costa, com a Corographia Portuguesa (1868/79). 
Curiosamente será só em Plantas e animais, para além de Barros Gomes e de diversos relatórios e documentos oficiais, que o nosso autor introduzirá a citação de dois geógrafos, diametralmente opostos na cronologia, E. Reclus e Estrabão. Por fim, no capítulo, Os Homens, onde avoca contributos dos mais variados, pontuam autores, como F. Martins Sarmento e outros investigadores ligados ainda ao Célebre Congresso Internacional de Antropologia e de Archeologia (1880), que reuniu entre nós, designadamente na excursão ao norte, alguns dos mais reputados investigadores da época; mas também cita, Estrabão; Michelet, com a sua Histoire de France... (1833-1867); Idácio; J. Contador de Argote; D. Francisco de S. Luís (Cardeal Saraiva); e o inevitável Alexandre Herculano.

Com este posicionamento, Alberto Sampaio, ainda que por demarcação de competências invoque o naturalista na abordagem que faz às matérias que daí são herança, e que justificam o escrutínio da crucial questão das origens da região e da razão de ser do Estado, podemos afirmar, expressam já uma "preocupação tipicamente positivista pelo rigoroso encadeamento causal dos factos unido á influência do evolucionismo lamarckiano, que valorizava as condiçóes do ambiente ecológico (...) base do chamado determinismo geográfico” (Capel, 1988: 295). Porém, como historiador assumido, reconhece que: "uma sociedade não rebenta espontaneamente do solo, nem se forma de jacto (...) cada invasor traz consigo o seu génio, o seu direito ou a sua civilização, fundindo-se tudo nas gentes e costumes anteriores (...) [Fazendo a comparação com uma árvore que,] antes de crescer, florir e frutificar, tem de se enraizar profundamente para aurir os princípios constitutivos. Como esta é também aquela. No longo decurso da existência social, o homem vai criando e adquirindo as diferentes instituiçóes que fazem a sua glória de 'ser' inteligente e consciente" (Sampaio, 1888, [2008]: 32).

Talvez por isso, possamos também de algum modo reconhecer o programa geográfico de Elisée Reclus, de que Sampaio desfruta em sua casa ao alcance da mão e que se organiza na seguinte sequência: "topografia e estrutura geológica; a circulação das águas; as forças subterrâneas; o oceano; a atmosfera e os meteoros; para depois estudar os fenómenos da vida; o homem e as suas adaptaçóes ao meio". 
Com efeito Alberto Sampaio não é de facto um naturalista, como o próprio afirma, e até, talvez por isso, conscientemente ou não, recorrerá à geografia disciplinar sobretudo como matéria e um método auxiliar de explicação da história. Contudo, pela sua sensibilidade intrínseca de investigador, pelo enraizamento do saber e a disseminação do conhecimento geográfico patente na sua obra, particularmente o que advém da vivência telúrica do território enquanto agricultor ilustrado, que o era verdadeiramente, tudo junto traduz um claro domínio antecipador, diríamos até, do que virá a ser mais tarde reivindicado como sendo o da ciência dos lugares.

\section{O legado geográfico de Alberto Sampaio}

Ao ter acrescentado mais de dez séculos à nossa história, como afirmou postumamente o seu amigo L. Magalhães Lima (1923), Alberto Sampaio, confrontado com as névoas do tempo e perscrutando os sulcos profundos do território minhoto, soube valorizar os processos, detetar as evidências mais perenes, bem para lá do hermetismo dos documentos, da exaltação dos egos e do culto das cronologias. Esta postura desde logo o predispôs para uma nova abordagem da história, inalienável da geografia e de outras mais áreas do conhecimento. Veja-se o exemplo da opção do autor pelo distanciamento à tese do ermamento, que reflete um raciocínio genuinamente geográfico, por ser também produto da observação direta, no caso, mais diversa do que foi o resultado da historiografia documental de Alexandre Herculano.

Por isso, não deixa, pois, de ser curioso que uma das principais historiógrafas de Sampaio nos confesse que a primeira vez que contactou a sua obra tenha sido através de Orlando Ribeiro, o mais referencial dos geógrafos portugueses. Recorde-se, o mesmo que comungou da classificação de "revolucionária" a introdução do milho maís no noroeste português, ou que estudou o pastoreio na Serra da Estrela (1941), referindo aí permanecerem muitos dos hábitos inalterados da Idade Média (Trindade, 1979: xv). Replicando, assim, a mesma atitude do historiador relativamente ao País do seu tempo, pela qual se reconhece a 
antecipação percursora do "método regressivo", anos mais tarde concretizado em novo paradigma historiográfico por Marc Bloch (1886-1944) através da célebre escola dos Annales (Mendes, 2008: 21). Isto é, fazer história ao revés, dos dias coevos até às origens, a partir do quadro vivo e dos processos longos que o investigador tinha diante dos olhos, e das provas materiais inscritas no subsolo, nas dimensōes contextuais das suas descobertas e, finalmente, da sua inscrição na paisagem, que a via como ninguém, porque era agricultor.

$\mathrm{Na}$ verdade o efetivo legado geográfico de Alberto Sampaio reconhece-se nos mais variados e disseminados trabalhos de geografia de Portugal. Desde logo nessa genealogia de saberes que une Alberto Sampaio a Orlando Ribeiro, de que são exemplo os estudos que este fez da relaçáo do território com a fundaçáo da nacionalidade, ou, muito particularmente, da abordagem aos domínios da geografia regional. Herança que também subsiste nas referências e asserçôes de geografia política, como notou mais recentemente Pedro Teles (2012), nos textos de António Sardinha (1887-1925), J. Paiva Boléo, Armando Gonçalves Pereira (1901-1983), Sérgio da Silva Pinto (1915-1970), A. Ferraz de Carvalho (1878-1955) e Eduardo Hernández Pacheco (1872-1965).

Daí para cá, o conhecimento desenvolvido por Alberto Sampaio enraizou-se através de numerosa literatura científica no domínio da geografia, muito particularmente de um modo indireto em tantas das suas especificidades, tais como: a geografia humana de Portugal; a geografia rural; a geografia regional; a geografia histórica; e, a geografia cultural, só para citar algumas das convençōes disciplinares da geografia contemporânea.

Mais não bastasse, ainda hoje a ideia de Minho, da natureza e dos seus antecedentes que podem determinar a origem da nacionalidade, o gérmen identitário das características do nosso estado-nação, tem em Alberto Sampaio um dos seus marcos incontornáveis. 


\section{Referências bibliográficas}

Alarcão, Jorge (1980). Os problemas da Origem e da Sobrevivência das 'Villae' Romanas do Norte do Pais - Sep. das Actas do Seminário de Arqueologia do Noroeste Peninsular - Guimaráes, Barcelos, pp. 3-11

Barroso da Fonte (1998). O Pensamento e a Obra de Alberto Sampaio. Dissertação de Mestrado, Guimarães, ed. de autor.

Besse, Jean-Marc (CNRS, UMR «Géographie-cités», Equipe E.H.GO) (2005). La géographie dans le mouvement des sciences au tournant du siècle. In Colloque "Autour de 1905: Elisée Reclus - Paul Vidal de la Blache. Le géographe, la cité, et le monde». Montpellier: Université Paul Valéry.

Capel, Horacio (1988). Filosofía y ciência en la Geografia contemporánea. Una introducción a la Geografia - Barcanova. 3.a ed., Barcelona: Temas universitarios.

Eco, Umberto (1987) - A Biblioteca. Lisboa: Difel.

Faria, Emília Sampaio Nóvoa(1995). Alberto Sampaio. Uma vida, uma obra. Actas do Congresso Histórico 150 anos do Nascimento de Alberto Sampaio. Câmara Municipal de Guimarães, pp. 19-28 .

Lemos, F. Sande (1992). Alberto Sampaio na arqueologia do seu tempo. Revista de Guimarães, N. ${ }^{\circ}$ 102: $371-386$

Martins, A. \& Faria Emília, Nóvoa (2007). 1. centenário de Alberto Sampaio. A Biblioteca da Casa de Boamense. Revista História, ano xxix (III série), N. ${ }^{\circ} 29$.

Mendes, J. Amado (2008). Introdução.In Alberto Sampaio, Obras. Guimarães: Sociedade Martins Sarmento, pp. 11-27

Pimenta, J. Ramiro M. Q. G. (2007). O 'Lugar do Passado' em Martins Sarmento. Geo-historiografia do programa de investigação arqueológica da 'Cultura Castreja' (1876-1899). Tese de Dout. Arque. Braga: Universidade do Minho.

Teles, Pedro Francisco F. Cabral (2011). Portugal Peninsular na Evolução do pensamento Geográfico Português (1904-1939). Tese de Dout.. Braga: Universidade do Minho.

\section{Fontes}

http://hal.inria.fr/docs/00/11/32/63/PDF/La_geographie_dans_le_mouvement_des_sciences_au_ tournant_du_siecle.pdf, Maio de 2012

Cartas de Alberto Sampaio (2009). Org. Introd. e notas de Emília Nóvoa Faria e António Martins. Correspondência - Volume II; V. ${ }^{a}$ N. ${ }^{a}$ de Famalicão: Húmus.

Cartas a Alberto Sampaio (2008). Org. Introd. e notas de Emília Nóvoa Faria e António Martins. Correspondência - Volume I; Porto: Campo das Letras. 